\title{
Recombinant porcine rotavirus VP4 and VP4-LTB expressed in Lactobacillus casei induced mucosal and systemic antibody
} responses in mice

\author{
Xinyuan Qiao1, Guiwei Li1 ${ }^{1}$, Xiangqing Wang ${ }^{1}$, Xiaojing $\mathrm{Li}^{1}{ }^{1}$, Min $\mathrm{Liu}^{2}$ and \\ Yijing Li*1
}

Address: ${ }^{1}$ Department of Preventive Veterinary, College of Veterinary, Northeast Agricultural University, 59 Mucai Street, Harbin, PR China and ${ }^{2}$ College of Animal Science and Technology, Northeast Agricultural University, 59 Mucai Street, Harbin, PR China

Email: Xinyuan Qiao - xinyuanqiao420@YAHOO.COM.CN; Guiwei Li - lgwzll@163.com; Xiangqing Wang -wangxiangqing@yahoo.com.cn; Xiaojing Li - lixiao_g@163.com; Min Liu - liumin-707@163.com; Yijing Li* - yijingli@yahoo.com

* Corresponding author

Published: 4 December 2009

BMC Microbiology 2009, 9:249 doi:10.1 I86/1471-2180-9-249
Received: 25 November 2008

Accepted: 4 December 2009

This article is available from: http://www.biomedcentral.com/I47I-2180/9/249

(C) 2009 Qiao et al; licensee BioMed Central Ltd.

This is an Open Access article distributed under the terms of the Creative Commons Attribution License (http://creativecommons.org/licenses/by/2.0), which permits unrestricted use, distribution, and reproduction in any medium, provided the original work is properly cited.

\begin{abstract}
Background: Porcine rotavirus infection is a significant cause of morbidity and mortality in the swine industry necessitating the development of effective vaccines for the prevention of infection. Immune responses associated with protection are primarily mucosal in nature and induction of mucosal immunity is important for preventing porcine rotavirus infection.
\end{abstract}

Results: Lactobacillus casei expressing the major protective antigen VP4 of porcine rotavirus (pPG6|2.I-VP4) or VP4-LTB (heat-labile toxin B subunit from Echerichia coli) (pPG6|2.I-VP4-LTB) fusion protein was used to immunize mice orally. The expression of recombinant PPG6/2.I-VP4 and PPG6I2.I-VP4-LTB was confirmed by SDS-PAGE and Western blot analysis and surfacedisplayed expression on $L$. casei was verified by immunofluorescence. Mice orally immunized with recombinant protein-expressing $L$. casei produced high levels of serum immunoglobulin $G(\lg G)$ and mucosal IgA. The IgA titters from mice immunized with PPG6I2.I-VP4-LTB were higher than titters from PPG6I2.I-VP4-immunized mice. The induced antibodies demonstrated neutralizing effects on RV infection.

Conclusion: These results demonstrated that VP4 administered in the context of an L. casei expression system is an effective method for stimulating mucosal immunity and that LTB served to further stimulate mucosal immunity suggesting that this strategy can be adapted for use in pigs.

\section{Background}

Rotaviruses are members of the family Reoviridae. Rotaviruses affecting pigs are classified as group A, B or C based on their respective inner capsid protein sequences[1]. The rotavirus double-stranded RNA genome is composed of 11 segments enclosed by a nonenveloped, triple-layered icosahedral capsid [2]. The outer capsid VP4 protein can induce neutralizing antibodies resulting in protecting herd from porcine rotavirus infection.

Porcine rotaviruses are the major cause of acute diarrhea in the piglets $[3,4]$ and can cause mild-severe diarrhea associated with potentially high morbidity and mortality. Group A rotaviruses cause diarrhea in pigs both before 
and after weaning [5] and can account for 53 and 44\% pre- and post-weaning rotavirus-associated diarrhea in swine, respectively [6]. A recent report attributed $89 \%$ of all rotavirus-associated diarrhea in commercial pig farms to group A rotavirus infections [7]. Since rotaviruses can survive in the environment for long period of time and are transmitted via the fecal-oral route outbreaks are difficult to control. Virion replication occurs at the tips of epithelial cell in intestinal villi and destroy enterocytes primarily in the jejunum and ileum resulting in villous atrophy $[8,9]$. Furthermore, nutrients cannot be digested or absorbed in the affected regions resulting in severe malabsorption [10]. A better understanding of rotavirus epidemiology will contribute to the optimization of current vaccines and prevention programs for the control of rotavirus infection. Currently available vaccines (mostly killed) can not offer efficient immunity. To stimulate efficient immunity, a large vaccine dose and repeated administration are usually required. This often results in undesirable clinical signs. To overcome these shortcomings, the potential development of lactic acid bacteria (LAB) to deliver heterologous antigen to the mucosal immune system has been proposed.

Since rotaviruses are enteric pathogens, mucosal immunity is likely to play an important role in protective immunity. Innate immune responses in gut provide the first line of defense against pathogenic microorganisms and also initiate acquired immune responses. Furthermore, immune responses resulting from oral immunization are the only suitable method of stimulating gut immunity [11] since this route facilitates stimulation of gut-associated lymphoid tissue (GALT) enhancing the production of anti-viral IgA [12].

Compared to recombinant antigens or heat-killed formulations, 'live' vaccines elicit the most effective protective responses since they stimulate both systemic and mucosal immunity [13-17]. However, oralvaccination presents a challenge since the gut milieu often denatures and/or inactivates potential vaccinogens therefore large vaccination doses and repeated vaccinations are required $[18,19]$. This often results in fecal shedding of the live vaccine in addition to causing fever and diarrhea $[16,18,19]$. These challenges can be overcome by using lactic acid bacteria (LAB) as antigen delivery system for the stimulation of mucosal immunity [20-25] owing to its safety. LAB are used in industrial food fermentation, preservation and have beneficial effects on the health of both humans and animals and 'generally regarded as safe, (GRAS'microorganisms). In addition, many strains of LAB are able to survive and colonize the intestinal tract $[26,27]$ inducing a non-specific immunoadjuvant effect [28] which prompted studies aimed at determining the oral vaccine potential of LAB-derived vaccines.

Since genetically engineered vaccines composed of a single recombinant antigen are poorly immunogenic, it is important to increase their immunogenicity by combining with appropriate adjuvants. The E. coli heat-labile toxin B subunit (LTB) has been shown to be a potent mucosal adjuvant [29-33] with low potential of eliciting allergic responses [34,35].

In this study, we tested the efficacy of the L. casei ATCC 393 expressing the heterologous VP4 porcine rotavirus protein and its ability acting as an antigen delivery system for oral vaccinations. We constructed recombinant strains expressing porcine rotavirus VP4 and VP4-LTB. The immunogenic potential of the two recombinant strains was analyzed after oral administration of live bacteria to mice. This is the first report describing the cloning and expression of porcine rotavirus genes in Lactobacillus. The data reported indicate that oral administration of two recombinant strains pPG612.1-VP4 or pPG612.1-VP4LTB could induce specific anti-rotavirus mucosal and systemic immune responses. The potency of the immune responses measured was greater in animals immunized with L. casei-expressing the VP4-LTB fusion (compared to mice immunized with $L$. casei expressing VP4 only) demonstrating the efficacy of LTB as a mucosal adjuvant.

\section{Results}

\section{Expression of VP4 and VP4-LTB in L. casei}

The sequences of the respective $L$. casei 393 transformants are confirmed by plasmid DNA sequencing and the result shows that there is no mutation in the transformants (data not shown).

rLc393:pPG612.1-VP4 and pPG612.1-VP4-LTB were grown in basal MRS medium supplemented with either xylose or glucose. Cell lysates subjected to SDS-PAGE and showed the corresponding VP4 and VP4-LTB recombinant proteins at 27 and $40 \mathrm{kDa}$ respectively after analyzing by Coomassie blue staining, following xylose induction (Figure 1A, lane 3 and Figure 1B, lane 3). Proteins were not expressed if cells were grown in basal MRS medium supplemented with glucose (Figure 1A, lane 2 and Figure $1 \mathrm{~B}$, lane 2). Gels run in parallel were transferred onto nitrocellulose membranes and examined by Western blot analysis using anti-VP4 antibodies. Immunoreactive bands corresponding to VP4 and VP4-LTB were observed at 27 and $40 \mathrm{kDa}$, respectively (Figure 2A, lane 2 and Figure 2B, lane 2). Reactive bands were not detected if the cells were instead grown in the presence of glucose (Figure 2A, lane 3 and Figure 2B, lane 1). These results 


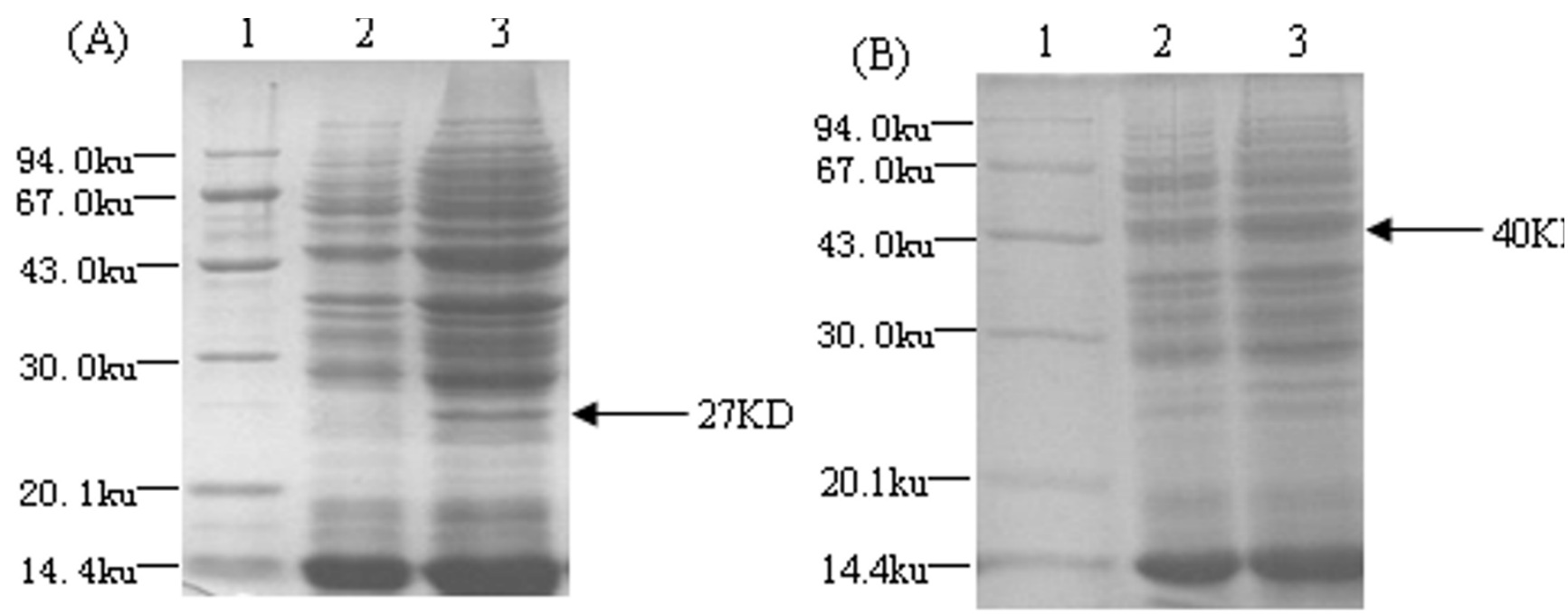

Figure I

Expression of VP4 and VP4-LTB in rLc393:pPG6 I 2. I-VP4 and pPG6 I 2. I-VP4-LTB. Total cell lysates were analysed by SDS-PAGE. Coomassie blue gel staining shows the expression of a $27 \mathrm{KD}$ and $40 \mathrm{KD}$ fusion protein in lysates of rLc393 induced by xylose (Fig. IA, lane 3 and Fig. IB, lane 3), but not in basal MRS with glucose (Fig. IA, lane 2 and Fig. IB, lane 2).

demonstrated the efficiency and specificity of the L. casei xylose promoter.

\section{Immunofluorescence analysis}

L. casei surface-displayed expression of VP4 and VP4-LTB, respectively, was confirmed by immunofluorescence. Overnight cultures of pPG612.1-VP4 and pPG612.1-VP4LTB were grown in basal MRS medium supplemented with either xylose or glucose. The cells were washed, incubated with mouse anti-VP4 anti serum followed by a FITC-conjugated goat anti-mouse IgG. VP4 was detected on the surface of pPG612.1-VP4 and pPG612.1-VP4-LTB cells grown in the presence of xylose (Figure $3 \mathrm{~B}$ and $3 \mathrm{C}$ ). No immunofluorescence was observed when wild-type $L$. casei 393 was incubated in a similar fashion (cells were stained red by Evans blue dye, Figure 3A).

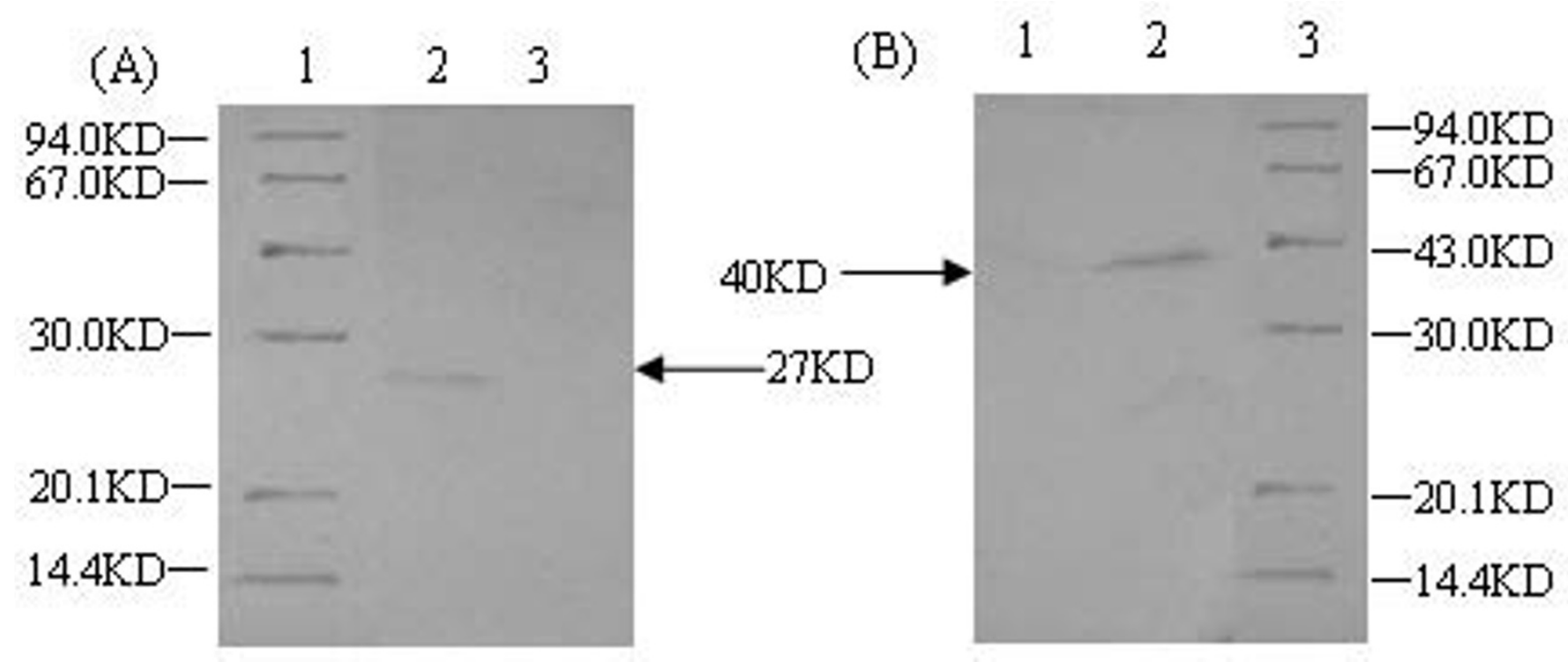

Figure 2

Western-blotting analysis of VP4 and vp4-LTB expression in recombinant strain. Immunoreactive bands were observed (Fig. 2A, lane 2 and Fig. 2B, lane 2) in the similar position as shown in the SDS-PAGE, however, there were no immunoblots in the same cell lysates induced by glucose (Fig. 2A, lane 3 and Fig. 2B, lane I). 

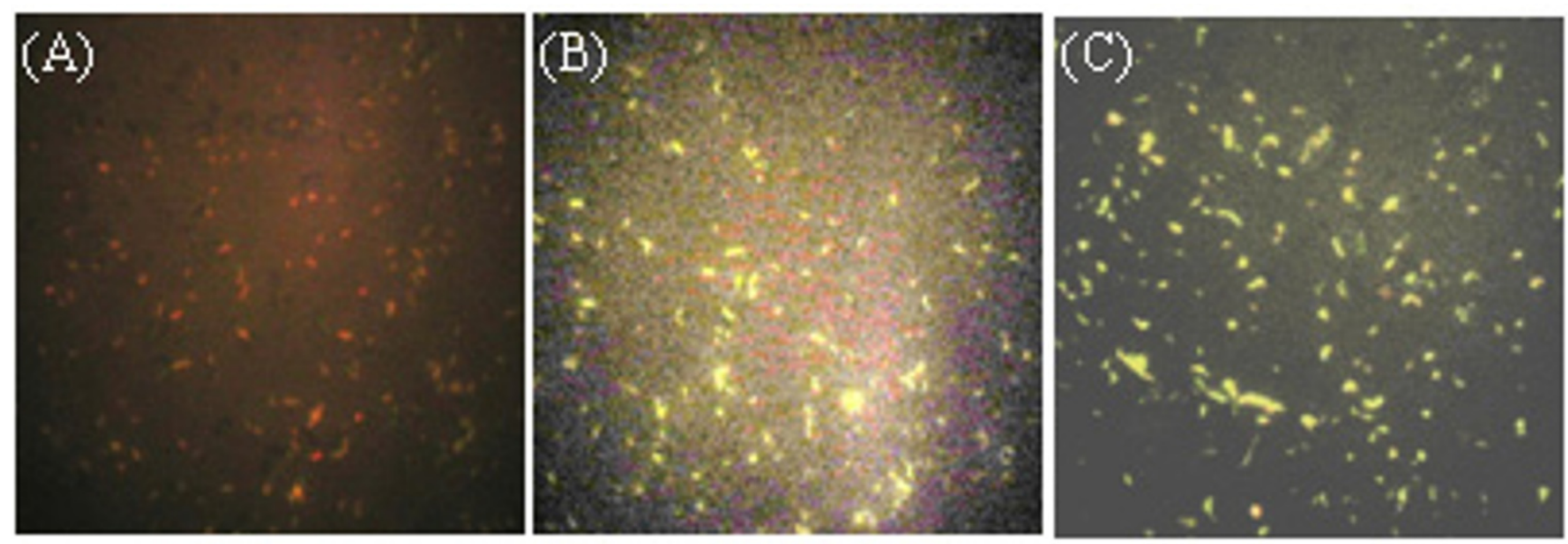

\section{Figure 3}

Immunofluorescence analysis. Wild-type L. casei 393 was induced by xylose, the result of immunofluorescence was negative, and the cells were dyed red by Evans blue (A). When PPG6/2.I-VP4 and PPG6/2.I-VP4-LTB were induced by xylose, there were green-yellow fluorescence reaction on the surface of the cells $(B, C)$.

\section{Antibody responses following oral immunizations}

The ability of the respective VP4-expressing $L$. casei vectors to elicit systemic and/or mucosal immunity was assessed by determining the presence of anti-VP4 IgG and IgA antibodies, respectively. Anti-VP4 IgG antibody levels in serum of mice treated with either pPG612.1-VP4 or pPG612.1-VP4-LTB were similar to each other but higher than only with pPG612.1 (Figure 4). After the first booster, a prompter and stronger level of anti-VP4-specific

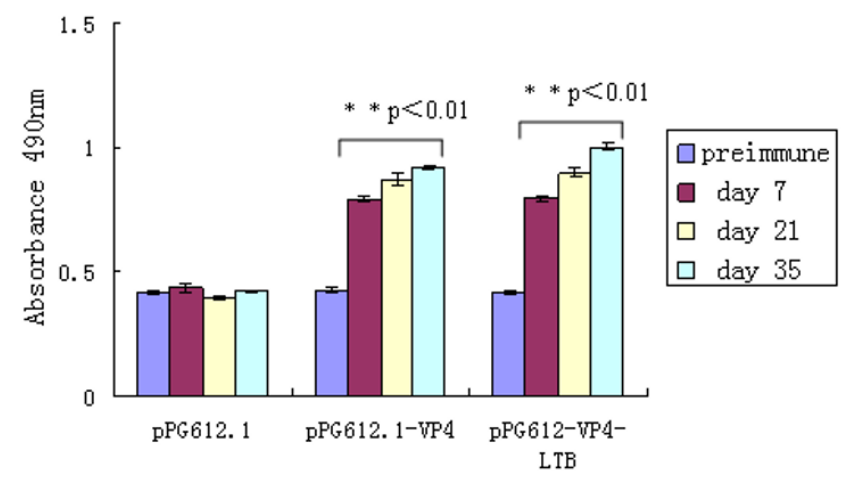

\section{Figure 4}

Specifis IgG antibodies in serum. Serum from groups of mice (I0 mice every group) immunized orally with PPG6 |2.I-VP4, PPG6|2.I-VP4-LTB and equivalent dose of PPG6 I2.I were analyzed for the presence of anti-VP4 specific IgG by ELISA. IgG titers of serum in mice given PPG6 I 2. I-VP4 or PPG6 I2. I-VP4-LTB were similar but higher than that of mice given PPG6I2.I. ** $P<0.01$ significant difference between IgG titers of serum in mice given PPG6I2.I-VP4 and PPG6I2.I on day 7, 21 and 35. Results are the $\lg G$ titers \pm standard errors of the means in each group. serum IgG was elicited in mice that were administered with recombinant strains. A statistically significant difference was observed on day 7, 21 and $35\left({ }^{* *} \mathrm{P}<0.01\right.$, Figure 4). No significant elicitation of anti-VP4 antibodies was observed in the control groups that received pPG612.1.

As the results showed, there were no substantial differences in mucosal IgA levels between experimental and control groups prior to oral immunization. Following administration with the $L$. casei recombinants, specific anti-VP4 mucosal IgA responses were observed. After the second boost, significant levels of anti-VP4 IgA were observed from mucosal secretions following administration of either pPG612.1-VP4 or pPG612.1-VP4-LTB compared to responses observed in control mice. Statistically significant difference $\left({ }^{* *} \mathrm{P}<0.01\right.$, Figure 5 and 6 ) was observed in ophthalmic and vaginal wash of mice administered with recombinant strains after seven days and fecal pellets after one day. The mucosal IgA levels elicited by pPG612.1-VP4-LTB were higher than pPG612.1-VP4 immunization and the difference is significant statistically $\left({ }^{*} \mathrm{P}<0.05,{ }^{*} \mathrm{P}<0.01\right.$, Figure 5 and 6$)$. This indicated that LTB enhanced the mucosal immune system response.

\section{Neutralization ability of the induced antibodies analysis}

The Neutralization ability of the induced antibodies was investigated to further detect whether the antibody responses were against RV. Results demonstrated that the presence of anti-rPRV-VP4 IgG in the culture medium conferred statistically significant neutralizing effects $\left({ }^{* *} \mathrm{P}\right.$ $<0.01$, Figure. 7) on RV infection. A near $50.28 \% \pm 0.83 \%$ reduction of CPE was consistently observed when the assays were carried out using 2-to 16-fold diluted sera 


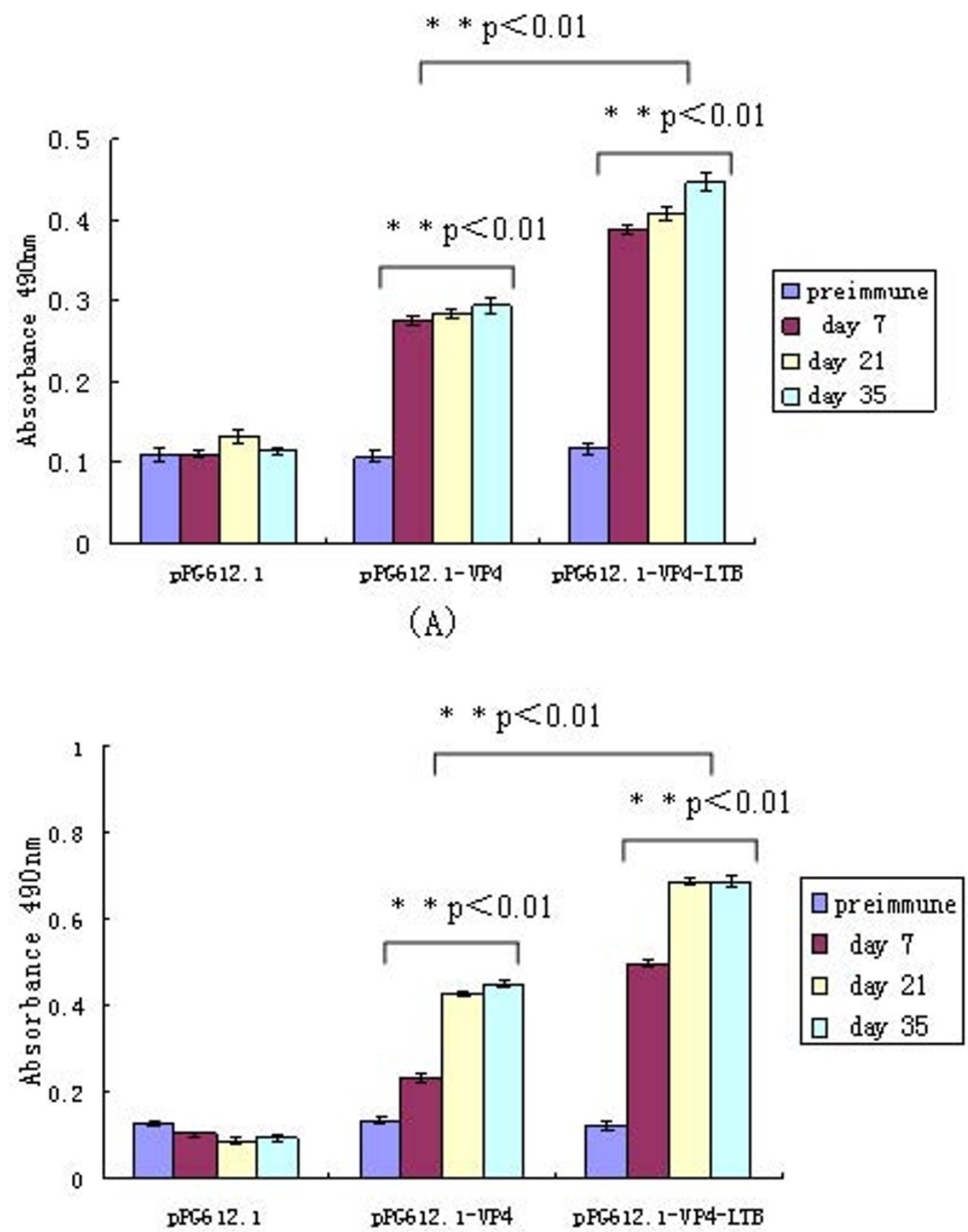

(B)

\section{Figure 5}

Specific IgA levels in ophthalmic and vaginal wash were detected after oral immunization ( 10 mice every group administered with different recombinant strains). Specific IgA antibody titers were detectable in the mice immuned with PPG6I2.I-VP4 and PPG6I2.I-VP4-LTB after the first administration (Fig. 5A, B). Statistically significant difference $(* * P<0.01)$ was observed in ophthalmic and vaginal wash of mice administered with recombinant strains after seven days. IgA levels elicited by PPG6I2. I-VP4-LTB were higher than those elicited following PPG6I2.I-VP4 immunization and the difference is significant statistically $(* * P<0.01)$. Bars represent the IgA titers \pm standard errors of the means in each group. 


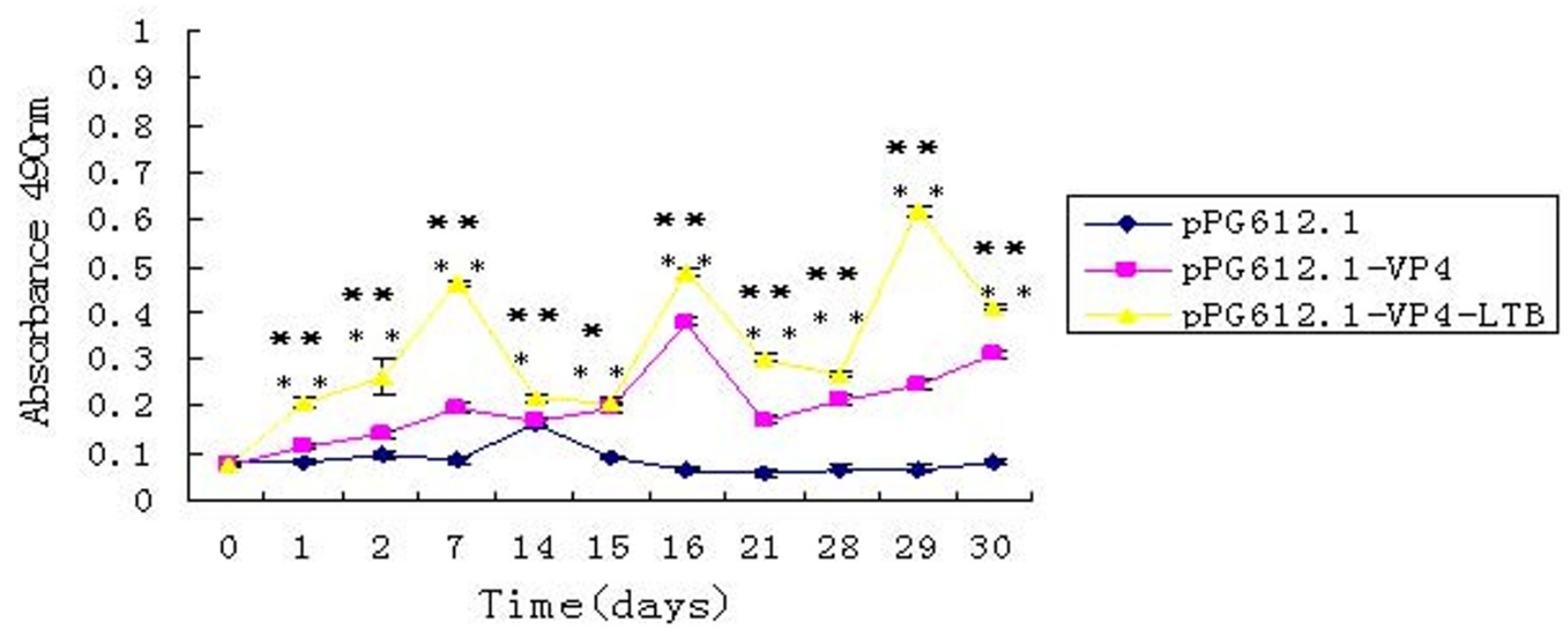

\section{Figure 6}

Specific IgA levels in fecal pellets after oral immunization. The mice ( 10 every group) received three consecutive immunization, three times at 2-week intervals. The control group of mice received the same dose of pPG6I2.I. Fecal pellets were collected I, 2, and 7 days after every immunization. Both of the groups immuned with PPG6I2.I-VP4 or PPG6I2.I-VP4LTB produced specific IgA. Statistically significant difference $(* * P<0.0 I)$ was observed in fecal pellets of mice administered with recombinant strains after one day. The levels of IgA in fecal pellets induced by pPG6I2.I-VP4 appeared lower than those induced by PPG6I2.I-VP4-LTB (*P $<0.05$, $*$ P $<0.01)$. Results are the IgA titers \pm standard errors of the means in each group.

from mice immunized with pPG612.1-VP4, and a 56.06\% $\pm 0.77 \%$ reduction of CPE was observed by using 2 -to 16 fold diluted sera from mice immunized with pPG612.1VP4-LTB. The inhibitory effect decreased gradually on further dilutions of sera and reached to the level similar to that of the control, which of sera administered with pPG612.1-VP4 is 1:128 and pPG612.1-VP4-LTB is 1:256 in Figure. 7. The neutralizing efficacy of anti-VP4 IgG from mice immunized with pPG612.1-VP4 was lower than pPG612.1-VP4-LTB and the difference was significant statistically $\left({ }^{*} \mathrm{P}<0.05,{ }^{*}{ }^{*} \mathrm{P}<0.01\right.$, Figure. 7$)$.

\section{Discussion}

Porcine rotaviruses are the major cause of acute diarrhea in the piglets and can cause mild to severe diarrhea with potentially high morbidity and mortality rates. Infection with porcine rotavirus has been an economic concern to worldwide pig breeders. Vaccination is the main prophylatic method for the prevention of porcine rotavirus infections. Mucosal immunization offer a number of advantages over other routes of antigen delivery, including ease of administration, cost effectiveness and the capacity of inducing both local and systemic immune responses [36-41].

To assess mucosal immune responses, specific IgA antiVP4 protein levels were examined from various mucosal surfaces. Oral administration of recombinant VP4 or VP4-
LTB-expressing L. casei induced both systemic (IgG) and mucosal (IgA) immune responses. Specifically, IgA specific for VP4 could be isolated from the gastrointestinal tract, vagina and eye secretions compared to no detectable IgA anti-VP4 responses in control animals. These experiments suggested that $L$. case $i$ expressing recombinant VP4 could be used in the vaccination of pigs, potentially protecting them from porcine rotavirus infections since this vector successfully elicited a significant and specific antiVP4 IgA response.

The titers of anti-VP4 IgG in the serum from mice immunized with the L. casei pPG612.1-VP4 or pPG612.1-VP4LTB were similar but higher than the control group. rLc393:pPG612.1-VP4-LTB induced even higher IgA specific for VP4 compared to mice immunized with the pPG612.1-VP4 as a result of the LTB mucosal adjuvant. It demonstrated the specific mucosal adjuvanticity of LTB, highlighting its potential use as a safe and effective mucosal adjuvant that can be used in conjunction with VP4 for the elicitation of specific anti-porcine rotavirus immunity.

Furthermore, in order to confirm the efficacy of the induced antibodies in inhibiting the virus, we tested whether sera collected from immunized mice could inhibit the infection of RV in MA104 cells by neutralization ability assay. The results showed that serum collected 


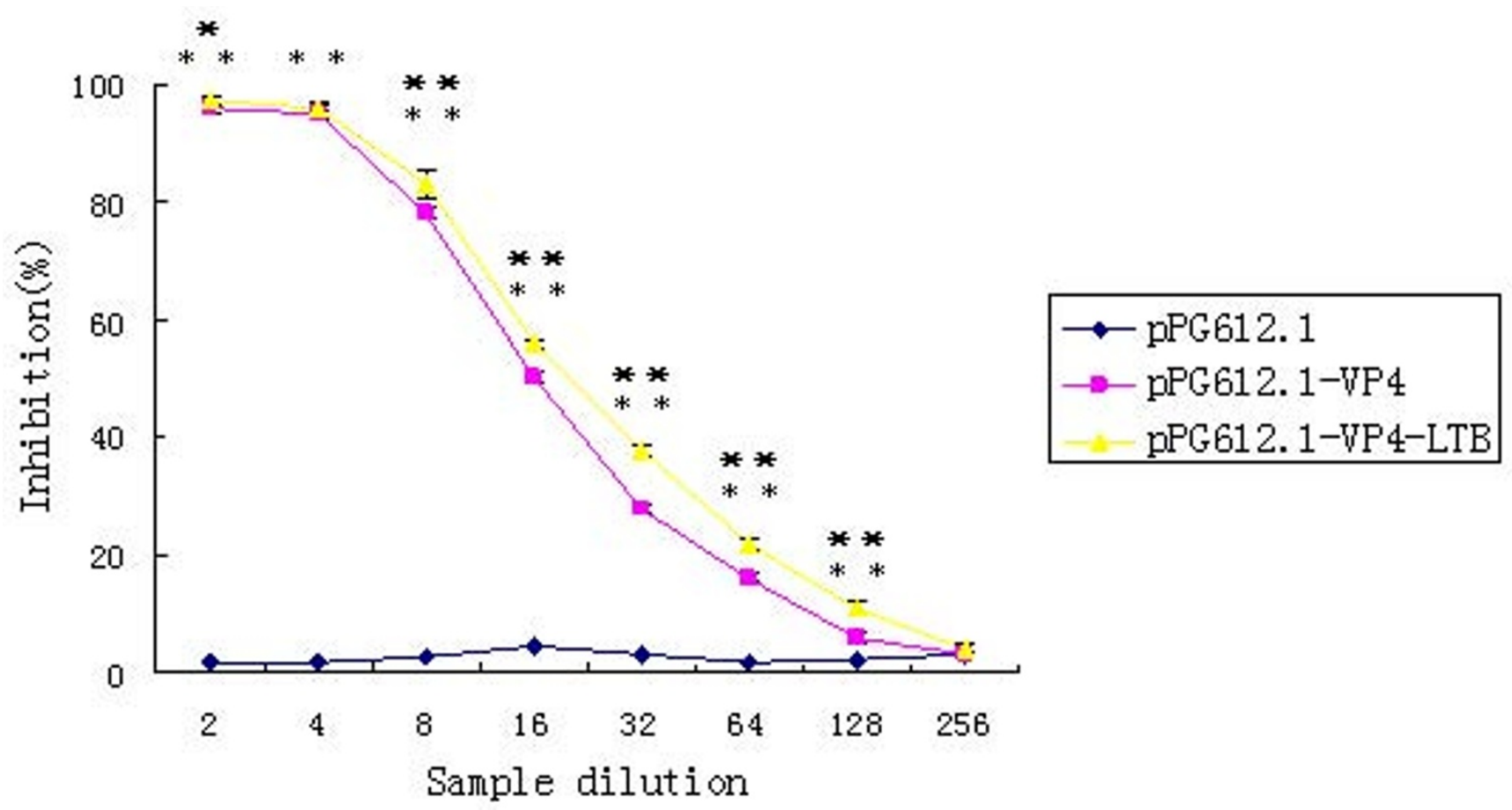

\section{Figure 7}

Neutralization ability of the sera prepared from mice immunized with pPG6 I 2. I-VP4 and pPG6 I 2. I-VP4-LTB. The maximum reduction of CPE, expressed as a percentage of CPE obtained for the negative control samples, by using sera collected from mice fed with PPG6I2.I-VP4 or PPG6I2.I-VP4-LTB, was $50.28 \% \pm 0.83 \%$ or $56.06 \% \pm 0.77 \%$, respectively. Statistically significant difference $(* * P<0.01)$ was observed in sera of mice administered with recombinant strains. The neutralizing efficacy of anti-VP4 lgG from mice immunized with PPG612.I-VP4 was lower than antibodies obtained from mice immunized with PPG6I2. I-VP4-LTB and the difference was significant statistically $(* P<0.05$, $* * P<0.0 I)$. Results are mean values and standard errors (error bars) of triplicates.

from mice immunized with recombinant strains demonstrated statistically significant inhibition. The neutralization by sera antibodies obtained from mice immunized with pPG612.1-VP4-LTB was more effective than that of mice immuned with the pPG612.1-VP4.

\section{Conclusion}

In this report, we described the methods for constructing two $L$. casei recombinant expression vectors expressing the porcine rotavirus VP4 antigen or VP4-LTB fusion protein. $L$. casei is an excellent delivery vector since it can withstand the rigors of the intestinal environment in addition to being able to colonize different mucosal sites (gastrointestinal and genital tracts) and guaranteeing proper (intact) presentation of the respective antigens to the immune system. In addition to the versatility of $L$. casei, it possesses probiotic properties making it an even more attractive vaccine delivery system i.e., immunization with L. casei expressing VP4-LTB elicited potent anti-VP4 IgA responses. Testing the efficacy in a porcine vaccination and infection model is a next step in testing the efficacy of this vaccine formulation.

\section{Methods}

\section{Strains and culture conditions}

L. casei ATCC 393 (a kind gift of Jos Seegers, NIZO, The Netherlands) was grown anaerobically in MRS broth (Sigma, St, Louis, MO) at $37^{\circ} \mathrm{C}$ without shaking. To analyze protein expression, transformed $L$. case $i$ were grown in basal MRS medium ( $10 \mathrm{~g}$ peptone, $8 \mathrm{~g}$ beef extract, $4 \mathrm{~g}$ yeast extract, $2 \mathrm{~g}$ potassium phosphate, $5 \mathrm{~g}$ sodium acetate, $1 \mathrm{ml}$ Tween $80,2 \mathrm{~g}$ diammonium citrate, $0.2 \mathrm{~g}$ magnesium sulfate, and $0.05 \mathrm{~g}$ manganese sulfate per liter) supplemented with $2 \%$ xylose. L. casei was plated on MRS medium with $1.5 \%$ agar. The antibiotic concentration used for the selection of lactobacilli transformants was 10 $\mu \mathrm{g} / \mathrm{ml}$ of chloromycetin $(\mathrm{Cm}$; Sigma). Porcine rotavirus JL94 (belonging to P[7]) was conserved in the laboratory.

\section{Mice}

Balb/c mice (female) weighing 25-30 g (7 weeks of age) were obtained from the inbred colony maintained at the Harbin Veterinary Research Institute. Each experimental and control group consisted of 10 mice. The animals were fed balanced rodent food and water ad libitum. The mice 
were handled and maintained under strict ethical conditions according to the international recommendations for animal welfare and the Ethical Committee for animals sciences of HeiLongJiang province (032/2006).

\section{Mouse anti-VP4 antibodies}

The mouse anti-VP4 antibodies used in Western-blot and immunofluorescence analysis had been prepared and stored in our laboratory. The recombinant plasmid VP4pGEX-6P-1 was constructed and transformed into E. coli BL21(Yan Song). The recombinant strain was induced with IPTG. The serum was obtained from the Balb/c mice immunized with the purified VP4 protein. Western-blot test and neutralization test circumstantiate the expressed protein has biological activity(data not shown).

\section{Expression plasmid construction}

The pPG612.1 plasmid is an expression vector containing an ssUsp signal peptide secretion sequence (kindly supplied by Jos Seegers, NIZO, The Netherlands). Nucleic acid manipulation and cloning procedures were performed according to standard procedures [42]. All DNA manipulations were performed according to standard procedures [43]. A gene fragment about 756 bp (VP8) encoding the main structural polypeptide of VP4 (obtained from the genome of PRV strain JL94) was amplified by polymerase chain reaction (PCR) using forward primer 5'-CAGGGATCCAATGGCTTCGCTCA$3^{\prime}($ BamHI site underlined) and the reverse primer 5'GGCCTCGAGAGCTCTTGTGTGCA-3' (XhoI site underlined) (Figure 8). PCR amplification conditions were as follows: $95^{\circ} \mathrm{C}, 5 \mathrm{~min}$ followed by 30 cycles at $94^{\circ} \mathrm{C}, 1$ $\min ; 56.5^{\circ} \mathrm{C}, 1 \mathrm{~min} ; 72^{\circ} \mathrm{C}, 1 \mathrm{~min}$ and a $72^{\circ} \mathrm{C} 10 \mathrm{~min}$ final extension. The VP4 gene PCR product was cleaved with BamHI and $\mathrm{XhoI}$ and ligated into the corresponding sites of pPG612.1 digested with BamHI and XhoI, respectively, giving rise to pPG612.1-VP4. A gene fragment of about 375 bp encoding the $E$. coli LTB structural polypeptide was amplified by PCR using the forward primer 5'AAGGTCGACTGCTGTVVGATGAATAAAGTAAAATGT-

TAT-3' (Sall site underlined) and the reverse primer 5'AAGCTCGAGCTAGTTTTCCATACTGATTGCCG-3'(XhoI site underlined). PCR amplification conditions were as follows: $95^{\circ} \mathrm{C}, 5 \mathrm{~min}$ followed by 30 cycles of $1 \mathrm{~min}$ at $94^{\circ} \mathrm{C} ; 1 \mathrm{~min}, 56^{\circ} \mathrm{C} ; 1 \mathrm{~min}, 72^{\circ} \mathrm{C}$ and a final extension at $72^{\circ} \mathrm{C}$ for $10 \mathrm{~min}$. The LTB PCR product was cleaved with SalI and XhoI and inserted into the corresponding sites in pPG612.1-VP4 digested with SalI and XhoI, giving rise to pPG612.1-VP4-LTB (Figure 8).

Electroporation of $L$. casei was carried out as previously described [44]. Briefly, plasmid DNA $(10 \mu \mathrm{l})$ was added to $150 \mu \mathrm{l}$ of L. casei 393 , gently mixed at $4{ }^{\circ} \mathrm{C}$ for $5 \mathrm{~min}$ and subjected to a single electric pulse ( $25 \mu \mathrm{F}$ of $2.5 \mathrm{kV} / \mathrm{cm}$ ). The mix was then incubated in MRS medium without $\mathrm{Cm}$

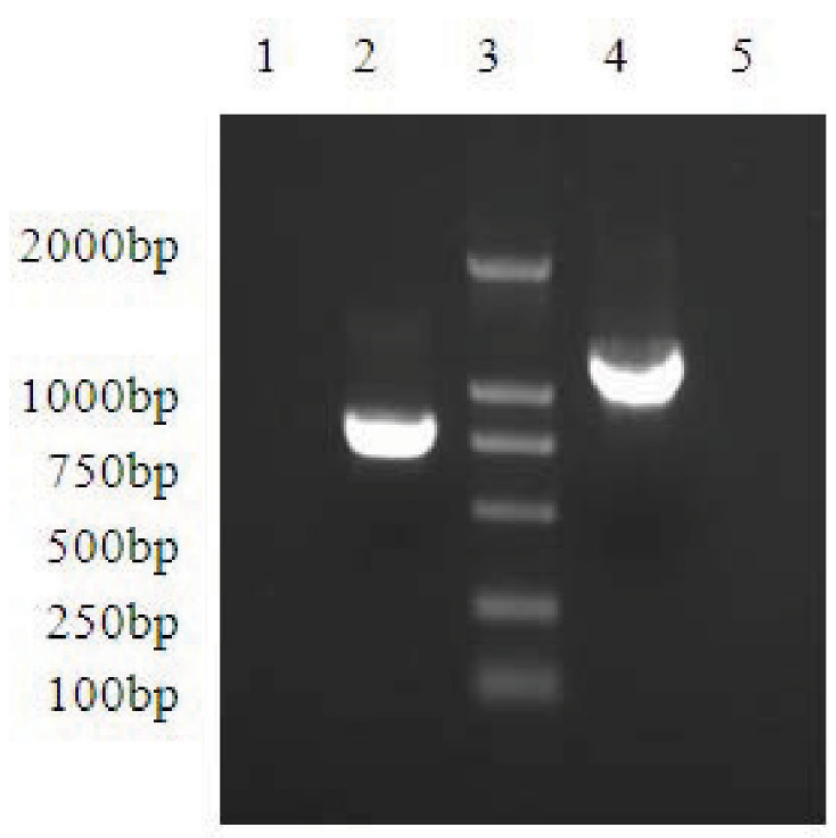

\section{Figure 8}

Target amplification fragments of VP4 and VP4-LTB fusion gene. Lane I,5: Blank controls; Lanes 2: Target amplification fragment of VP4 gene; Lanes 3: 2000 bp DNA marker; Lane 4:Target amplification fragment of VP4-LTB fusion gene.

at $37^{\circ} \mathrm{C}$ anaerobically for $2 \mathrm{~h}$. Recombinant strains were selected on MRS-agar medium containing $10 \mu \mathrm{g} / \mathrm{ml}$ of $\mathrm{Cm}$. The sequences of the respective $L$. casei 393 transformants were confirmed by plasmid DNA sequencing.

\section{Protein expression and Western-blot analysis}

To analyze the expression of the VP4 and VP4-LTB fusion protein following xylose induction of rLc393:pPG612.1VP4 and pPG612.1-VP4-LTB, respectively, overnight cultures grown in basal MRS broth supplemented with xylose (or glucose as a negative induction control) and pellets collected by centrifugation at $12,000 \times \mathrm{g}$ for $10 \mathrm{~min}$. The pellets were washed twice with sterile $50 \mathrm{mM}$ Tris-Cl, $\mathrm{pH}$ 8.0 and treated with $10 \mathrm{mg} / \mathrm{ml}$ lysozyme at $37^{\circ} \mathrm{C}$ for 60 $\mathrm{min}$. The lysates were centrifuged at $12000 \times \mathrm{g}$ for $10 \mathrm{~min}$ and subjected to $10 \%$ sodium dodecyl sulphate polyacrylamide gel electrophoresis (SDS-PAGE) and either stained with Coomassie blue or electrotransferred onto nitrocellulose membranes. The immunoblots were blocked with PBS containing $5 \%$ skimmed milk for $2 \mathrm{hr}$ at $37^{\circ} \mathrm{C}$. Blots were washed three times between all steps for ten minutes. Blots were incubated with 1:800 dilution $(100 \mu \mathrm{L})$ of mouse anti-VP4 antibodies in phosphate-buffered saline (PBS), washed and then probed with a horseradish peroxidase (HRP)-conjugated goat anti-mouse IgG (Sigma) diluted at 1:2500 $(100 \mu \mathrm{L})$ in PBS. The blots were washed 
and incubated with the Chemiluminescent Substrate reagent (Pierce, Rockford, IL) according to the manufacturer's instruction. Control blots incubated with secondary antibody only did not result in visible protein band reactivity.

\section{Immunofluorescence analysis}

Immunofluorescence was used to analyze VP4 and VP4LTB protein surface expression by either rLc393:pPG612.1-VP4 or pPG612.1-VP4-LTB as described previously [45]. Briefly, $2 \mathrm{ml}$ induced cultures were harvested to an OD600 $=0.5-0.6$ and then resuspended in 1 $\mathrm{ml}$ sterile PBS 3\% bovine serum albumin (BSA) containing anti-VP4 antibodies and then incubated overnight at $37^{\circ} \mathrm{C}$. The cells were then pelleted, washed 3 times with sterile PBS $0.05 \%$ Tween 20 . The cell-antibody complexes were then incubated for $6 \mathrm{~h}$ at $37^{\circ} \mathrm{C}$ in the dark with fluoreoscein isothiocyanate (FITC)-conjugated goat antimouse IgG (Sigma) containing 1\% Evans blue. Cells were washed 3 times with PBS $0.05 \%$, Tween 20 and then airdried on a glass slide. Analysis was performed using a confocal microscope. Non-induced or glucose-induced recombinant strains were used as negative controls.

\section{Immunizations}

rLc393:pPG612.1-VP4 and rLc393:pPG612.1-VP4-LTB were cultured and centrifuged as described above. Cell pellets were washed once with sterile PBS and resuspended in PBS ( $\mathrm{pH} 7.4$ ). Mice were orally vaccinated with $0.2 \mathrm{ml} 10^{9}$ colony-forming units (c.f.u.)/ml of the recombinant strains, respectively. A control group of 10 mice received $L$. casei ATCC 393 containing the empty plasmid was also included. Mice in all groups were immunized on days 0,1 and 2 and boosted on days 14, 15 and 16 and again on days 28,29 and 30 .

\section{Enzyme-linked immunosorbent assay (ELISA)}

Mouse serum was collected on days 7,14,21 and examined for specific anti-VP4 antibodies by ELISA. Feces was collected at 1,2 and 7 days after every immunization as described previously [46]. Ophthalmic washes were obtained by washing the eyes with $50 \mu \mathrm{l}$ PBS 7 days after every immunization. Vaginal washes were collected by washing the vagina with $200 \mu \mathrm{l}$ PBS 7 days after every immunization. All samples were stored at $-20^{\circ} \mathrm{C}$ until assayed by ELISA.

Polystyrene microtitre plates were coated overnight at $4{ }^{\circ} \mathrm{C}$ with either porcine rotavirus propagated on MA104 cells or with supernatants harvested from MA104 cells cultured without rotavirus as negative control. ELISA plates were washed 3 times with PBS 1\%Tween 20 and then blocked with PBS $5 \%$ skim milk at $37^{\circ} \mathrm{C}$ for $2 \mathrm{~h}$. Serum or mucosal wash samples were serially diluted in PBS $1 \%$ BSA and incubated at $37^{\circ} \mathrm{C}$ for $1 \mathrm{~h}$, washed 3 times and then incu- bated with a 1:2000 dilution $(100 \mu \mathrm{L})$ of an HRP-conjugated goat anti-mouse IgA (Sigma) or IgG (Sigma), washed and visualized following the addition of $100 \mu \mathrm{l}$ of o-phenylene diamine dihydrochloride substrate(Sigma). The absorbance was measured at $490 \mathrm{~nm}$. Differences in the samples between treatments were examined for the level of significance by ANOVA.

\section{Neutralization ability of the induced antibodies}

Serum samples from mice immunized with recombinant strains expressing VP4 or VP4-LTB were evaluated [47] to determine the neutralization ability of the induced antibodies. In brief, sera from mice fed with non-expressor strains was used as negative control. Fifty microliters of samples in serial dilutions (from 1:2 to 1:512) was prepared in a 96-cell plate. RV adjusted to 200 TCID50 in 50 $\mu \mathrm{L}$ of virus diluent (10\% concentrated Hanks balanced salt solution, $\mathrm{pH}$ 7.4) was added to the cell plate containing serially diluted serum. The mixture of antibody and virus was mixed and incubated at $37^{\circ} \mathrm{C}$ for $1 \mathrm{~h}$. Then 100 $\mu \mathrm{L}$ of MA104 cells (used for virus infection) was added to the antibody-virus mixture and incubated in a 5\% CO2 incubator at $37^{\circ} \mathrm{C}$ for 5 days. The overlay medium was then discarded, after which the wells were washed three times with sterile PBS, pH 7.4, and stained with $1 \%$ crystal violet solution. Differences in the number of plaques formed between treatments were examined for the level of significance by ANOVA.

\section{Statistical analysis}

Statistical significance was determined using ANOVA, with a $P$ value $<0.05$ considered as significant.

\section{Authors' contributions}

XQ carried out construction of expression plasmid, participated in the sequence alignment and drafted the manuscript. GL carried out the protein expression and immunoassays. XW and XL carried out the Immunizations. ML performed the statistical analysis. YL conceived of the study, and participated in its design and coordination. All authors read and approved the final manuscript.

\section{Acknowledgements}

This work was supported by grants from the National Science and Technology Foundation of China (No. 2006BAD06A07) and the Program for Innovative Research Team of NEAU (No. CXZ008). The authors wish to thank Jos Seegers for providing plasmid PPG6II.I and bacterial strain L. casei ATCC 393.

\section{References}

I. Paul PS, Lyoo YS: Immunogens of rotaviruses. Vet Microbiol 1993 , 37:299-317.

2. Estes MK: Rotaviruses and their replication. Fields Virology 200I, 4:1747-I785.

3. Rosen I, Parwani AV, Lopez S, Flores J, Saif L: Serotypic differentiation of rotaviruses in field samples from diarrheic pigs by using nucleic acid probes specific for porcine VP4 and human and porcine VP7 genes. J Clin Microbiol 1994, 32:3 I I-317. 
4. Winiarczyk S, Paul PS, Mummidi S, Panek R, Gradzki Z: Survey of porcine rotavirus $\mathbf{G}$ and $P$ genotype in Poland and the United States using RT-PCR. J Vet Med 2002, 49:373-378.

5. Gatti MS, Ferraz MM, Racz ML, de Castro AF: Rotavirus excretion in naturally infected pigs with and without diarrhea. Vet Microbiol 1993, 37: 187-190.

6. Fitzgerald GR, Barker T, Welter MW, Welter C): Diarrhea in young pigs: comparing the incidence of the five most common infectious agents. Vet Med Food Anim Pract 1988, I:80-86.

7. Will LA, Paul PS, Proescholdt TA: Evaluation of rotavirus infection in diarrhea in lowa commercials pigs based on an epidemiologic study of a population represented by diagnostic laboratory cases. J Vet Diagn Invest 1994, 6:416-422.

8. Shaw DP, Morehouse LG, Solorzano RF: Experimental rotavirus infection in three-week old pigs. Am J Vet Res 1989, 50:1961-1965

9. Moon HW: Comparative histopathology of intestinal infections. Adv Exp Med Biol 1997, 4I 2: I- 19.

10. Svensmark B, Askaa J, Wolstrup C, Nielsen K: Epidemiological studies of piglet diarrhea in intensively managed Danish sow herds. IV. Pathogenicity of porcine rotavirus. Acta Vet Scand 1989, 30:71-76.

II. Gerdts V, Mutwiri GK, Tikoo SK, Babiuk LA: Mucosal delivery of vaccines in domestic animals. Vet Res 2006, 37:487-5 I0.

12. Levine MM, Dougan G: Optimism over vaccines administered through mucosal surfaces. Lancet |998, 35 I: |375- | 376.

13. Kodama C, Eguchi M, Sekiya Y, Yamamoto T, Kikuchi Y, Matsui H: Evaluation of the Lon-deficient Salmonella strain as an oral vaccine candidate. Microbiol Immunol 2005, 49: I035-1045.

14. Segall $T$, Lindberg AA: Oral vaccination of calves with an aromatic-dependent Salmonella dublin $(09,12)$ hybrid expressing 04,12 protects against $S$. dublin $(09,12)$ but not against Salmonella typhimurium (04, 5, 12). Infect Immun 1993 61:|222-|23|

15. Smith BP, Reina-Guerra M, Hoiseth S, Stocker BA, Habasha F, Johnson E, Merritt FF: Aromatic-dependent Salmonella typhimurium as modified live vaccines for calves. Am J Vet Res 1984, 45:59-66.

16. Smith BP, Reina-Guerra M, Stocker BA, Hoiseth S, Johnson EH: Vaccination of calves against Salmonella dublin with aromaticdependent Salmonella typhimurium. Am J Vet Res 1984, 45: $|858-| 86 \mid$

17. Uren T, Wijburg OLC, Simmons C, Johansen F, Brandtzaeg $P$ Strugnell R: Vaccine-induced protection against gastrointestinal bacterial infections in the absence of secretory antibodies. Eur J Immunol 2005, 35: 180-188.

18. Smith BP, Dilling GW, Roden LD, Stocker BA: Vaccination of calves with orally administered aromatic-dependent Salmonella Dublin. Am J Vet Res 1993, 54: I249- 255.

19. Wray C, McLaren I: Further studies on the use of Gal E mutants of Salmonella typhimurium in calves: oral vaccination and toxicity studies. J Vet Med 1987, 34:22-29.

20. Pouwels PH, Leer RJ, Boersma WJ: The potential of Lactobacillus as a carrier for oral immunization: development and preliminary characterization of vector systems for targeted delivery of antigen. J Biotechnol 1996, 44:183-192.

21. Maassen CBM, Laman JD, Heijne MJ: Instruments for oral diseaseintervention strategies: recombinant Lactobacillus case expressing tetanus toxin fragment $\boldsymbol{C}$ for vaccination or myelin proteins for oral tolerance induction in multiple sclerosis. Vaccine 1999, 17:2117-2128.

22. Reveneau N, Geoffroy MC, Locht C: Comparison of the immune responses induced by local immunizations with recombinant Lactobacillus plantarum producing tetanus toxin fragment $\mathbf{C}$ in different cellular locations. Vaccine 2002, 20:1769-1777.

23. Scheppler L, Vogel M, Zuercher A: Recombinant Lactobacillus johnsonii as a mucosal vaccine delivery vehicle. Vaccine 2002 , 20:2913-2920.

24. Oliveria MLS, Monedero V, Miyaji EN, Leite LCC, Lee Ho P, PerezMartinez G: Expression of Streptococcus pneumoniae antigens, PsaA and PspA by Lactobacillus casei. FEMS Microbiol Lett 2003 227:25-31.

25. Ho PS, Wang JK, Lee YK: Intragastric administration of Lactobacillus casei expressing transmissible gastroentritis coronavirus spike glycoprotein induced specific antibody production. Vaccine 2005, 23:1335-42.
26. Alander M, Satokari R, Korpela R, Saxelin M, Vilpponen-Salmela T, Mattila-Sandholm T: Persistence of colonization of human colonicmucosa by a probiotic strain, Lactobacillus rhamnosus GG, after oral consumption. Appl Environ Microbiol 1999, 65:35I-354

27. Lee YK, Ho PS, Low CS, Arvilommi H, Salminen S: Permanent colonization by Lactobacillus casei is hindered by the low rate of cell division in mouse gut. Appl Environ Microbiol 2004, 70:670-674

28. Ogawa T, Asai Y, Yasuda K: Oral immunoadjuvant activity of a new symbiotic Lactobacillus casei subsp casei in conjunction with dextran in BALB/c mice. Nutrition Research 2005, 25:295-304.

29. Verweij WR, de Haan L, Holtrop M, Agsteribbe E, Brands R, van Scharrenburg G], Wilschut J: Mucosal immunoadjuvant activity of recombinant Escherichia coli heat-labile enterotoxin and its B subunit: induction of systemic IgG and secretory IgA responses in mice by intranasal immunization with influenza virus surface antigen. Vaccine 1998, 16:2069-2076.

30. Tochikubo K, Isaka M, Yasuda Y, Kozuka S, Matano K, Miura Y, Taniguchi T: Recombinant cholera toxin $B$ subunit acts as an adjuvant for the mucosal and systemic responses of mice to mucosally co-administered bovine serum albumin. Vaccine 1998, 16:150-155.

3I. Yamamoto M, McGhee JR, Hagiwara Y, Otake S, Kiyono H: Genetically manipulated bacterial toxin as a new generation mucosal adjuvant. Scand J Immunol 200I, 53:2II-2I7.

32. de Haan L, Feil IK, Verweij WR, Holtrop M, Hol WG, Agsteribbe E, Wilschut J: Mutational analysis of the role of ADPribosylation activity and GMI-binding activity in the adjuvant properties of the Escherichia coli heat-labile enterotoxin towards intranasally administered keyhole limpet hemocyanin. Eur J Immunol 1998, 28: I 243-1250.

33. Saito K, Shoji J, Inada N, Iwasaki Y, Sawa M: Immunosuppressive effect of cholera toxin $B$ on allergic conjunctivitis model in guinea pig. Jpn J Ophthalmol 200I, 45:332-338.

34. Tamura S, Hatori E, Tsuruhara T, Aizawa C, Kurata T: Suppression of delayed-type hypersensitivity and IgE antibody responses to ovalbumin by intranasal administration of Escherichia coli heat-labile enterotoxin B subunit-conjugated ovalbumin. Vaccine 1997, 15:225-229.

35. Douce G, Fontana M, Pizza M, Rappuoli R, Dougan G: Intranasal immunogenicity and adjuvanticity of site-directed mutant derivatives of cholera toxin. Infect Immun 1997, 65:282 I-2828.

36. Mannam P, Jones KF, Geller BL: Mucosal vaccine made from live, recombinant Lactococcus lactis protects mice against pharyngeal infection with Streptococcus pyogenes. Infect Immun 2004, 72:3444-3450.

37. Robinson K, Chamberlain LM, Schofield KM, Wells JM, Le Page RW: Oral vaccination of mice against tetanus with recombinant Lactococcus lactis. Nat Biotechnol 1997, 15:653-657.

38. Seegers JF: Lactobacilli as live vaccine delivery vectors: progress and prospects. Trends Biotechnol 2002, 20:508-5I5.

39. Shaw DM, Gaerthé B, Leer RJ, Van der Stap JG, Smittenaar C, Heijne Den Bak-Glashouwer M, Thole JR, Tielen FJ, Pouwels PH, Havenith $\mathrm{CE}$ : Engineering the microflora to vaccinate the mucosa: serum immunoglobulin $G$ responses and activated draining cervical lymph nodes following mucosal application of tetanus toxin fragment C-expressing lactobacilli . Immunology 2000, 100:510-518.

40. Xin KQ, Hoshino $Y$, Toda $Y$, Igimi $S$, Kojima $Y$, Jounai N, Ohba $K$, Kushiro A, Kiwaki M, Hamajima K, Klinman D, Okuda K: Immunogenicity and protective efficacy of orally administered recombinant Lactococcus lactis expressing surface-bound HIV. Env Blood 2003, 102:223-228.

41. Fagarasan S, Honjo T: Intestinal IgA synthesis: regulation of front-line body defences. Nat Rev Immunol 2003, 3:63-72.

42. Sambrook J, Fritisch EF, Maniatis T: Molecular Cloning: A Laboratory Manual. 3rd edition. New York: Cold Spring Harbor Laboratory; 200I.

43. Sambrook J, Fritisch EF, Maniatis T: Molecular cloning: a laboratory manual. 2nd edition. Cold Spring Harbor Laboratory Press, Cold Spring Harbor, NY; 1989.

44. Shifang J, Yinyu W, Xinhua G, Liandong $\mathrm{H}$ : The factors affected transformation efficiency of Lactobacillus by electroporation. Chin J Biotechnol 1998, 14:429-33. 
45. Cortes-Perez NG, Luis G: Mice immunization with live lactococci displaying a surface anchored HPV-16 E7 oncoprotein. FEMS Microbiol Lett 2003, 229:37-42.

46. McCluskie MJ, Davis HL: CpG DNA is a potent enhancer of systemic and mucosal immune responses against hepatitis $B$ surface antigen with intranasal administration to mice. J Immunol 1998, 161:4463-4466.

47. Ho PS, Wang JK, Lee YK: Intragastric administration of Lactobacillus casei expressing transmissible gastroentritis coronavirus spike glycoprotein induced specific antibody production. Vaccine 2005, 23:1335-42.

Publish with Bio Med Central and every scientist can read your work free of charge

"BioMed Central will be the most significant development for disseminating the results of biomedical research in our lifetime. "

Sir Paul Nurse, Cancer Research UK

Your research papers will be:

- available free of charge to the entire biomedical community

- peer reviewed and published immediately upon acceptance

- cited in PubMed and archived on PubMed Central

- yours - you keep the copyright

Submit your manuscript here:

http://www.biomedcentral.com/info/publishing_adv.asp
BioMedcentral 